\title{
Model Predictions of Metal Speciation in Freshwaters Compared to Measurements by In Situ Techniques
}

\author{
Emily R. Unsworth, $\mathbf{t}$ Kent $\mathbf{w}$. Warnken, + Hao Zhang, + William Davison, $* \dagger$ \\ Frank Black, $\$$ Jacques Buffle,, $\mathbf{J}$ Jun Cao, $\$$ Rob Cleven, $\perp$ Josep Galceran, \\ Peggy Gunkel, \\ Michel Martin, $\$$ Stéphane Noël, $\$$ Yusuf Nur, $\perp$ Niksa Odzak, $\$$ Jaume Puy, \\ Willem van Riemsdijk, $\bowtie$ Laura Sigg, + Erwin Temminghoff, $\otimes$ Mary-Lou \\ Tercier-Waeber, $\$$ Stefanie Toepperwien, $\$$ Raewyn M. Town,\# Liping \\ Weng, $\bowtie$ and Hanbin Xuef
}

Department of Environmental Science, University of Lancaster, Lancaster LA1 $4 Y Q$, United Kingdom, and EAWAG, Swiss Federal Institute for Environmental Science and Technology, P.O. Box 611, CH-8600 Duebendorf, Switzerland, and Chimie Analytique et Biophysicochimie de l'Environnment, CABE, University of Geneva, Section de Chimie - Sciences II, 30 Quai Ernest-Ansermet, CH-1211 Geneva 4, Switzerland, and Laboratory for Inorganic Analytical Chemistry, Rijksinstituut voor Volksgezondheid en Milieu, Antonie van Leeuwenhoeklaan 9, P.O. Box 1, Bilthoven, 3721 BA, The Netherlands, and Departament de Química, Universitat de Lleida, Avda. Rovira Roure 191, E-25198 Lleida, Spain, and Department of Soil Quality, Wageningen University, Dreijenplein 10, P.O. Box 9101, Wageningen, 6703 HB, The Netherlands, and Laboratory of Physical Chemistry and Colloid Science, Wageningen University, Dreijenplein 6, P.O. Box 8038, Wageningen 6703 HB, The Netherlands, and Department of Chemistry, University of Southern Denmark, Campusvej 55, DK-5230 Odense, Denmark

\section{Abstract:}

Measurements of trace metal species in situ in a softwater river, a hardwater lake, and a hardwater stream were compared to the equilibrium distribution of species calculated using two models, WHAM 6, incorporating humic ion binding model VI and visual MINTEQ incorporating NICA-Donnan. Diffusive gradients in thin films (DGT) and voltammetry at a gel integrated microelectrode (GIME) were used to estimate dynamic species that are both labile and mobile. The Donnan membrane technique (DMT) and hollow fiber permeation liquid membrane (HFPLM) were used to measure free ion activities. Predictions of dominant metal species using the two models agreed reasonably well, even when colloidal oxide components were considered. Concentrations derived using GIME were generally lower than those from DGT, consistent with calculations of the lability criteria that take into account the smaller time window available for the flux to GIME. Model predictions of free ion activities generally did not agree with measurements, highlighting the need for further work and difficulties in obtaining appropriate input data. 
Environ. Sci. Technol., 40 (6), 1942 -1949, 2006.

\section{Introduction}

Measurements of metal speciation in natural waters are challenging: methods must be both very sensitive for low concentrations and specific for distinction between chemical species. Few studies have attempted to compare model predictions of metal speciation (1-4) to experimental in-field results due to the difficulties of making accurate measurements of chemical speciation directly on natural waters. Measurements of free ion activity can be compared directly with predictions from speciation models. However, dynamic techniques that measure fluxes, such as diffusive gradients in thin-films (DGT) and stripping voltammetry (SV), determine concentrations of a range of species as defined by the characteristic time scale of the technique. Recent modeling developments, that consider metal speciation dynamics in natural waters in relation to measurements by flux-based techniques, provide an interpretational framework (5).

Critical assessment of the applicability of equilibrium-based models is very timely in view of the drive to incorporate the biotic ligand model (BLM) into the regulatory framework (6). The BLM incorporates an equilibrium metal speciation program such as MINEQL+ $(7)$ or WHAM V $(6,8)$ to calculate metal speciation in solution, including metal binding to dissolved organic matter, and an equilibrium model for competitive binding at the surface of the biological membrane. Validation of this approach requires assessment of the accuracy of the model prediction of the distribution of species in natural waters.

Sampling and handling of waters can introduce changes in the distribution of species prior to measurement. In situ measurement avoids problems due to (1) contamination during sampling and storage, (2) instability of metal species during transport and storage prior to measurement, through processes associated with aggregation, reequilibration of gaseous components and precipitation, and (3) metal adsorption to container walls (9). In a collaborative study involving several laboratories, in situ measurements of $\mathrm{Cd}, \mathrm{Cu}, \mathrm{Ni}$, and $\mathrm{Pb}$ were made in three freshwaters with four different speciation techniques (10). Permeation liquid membranes (PLM) $(11,12)$ and the Donnan membrane technique (DMT) $(13,14)$ were used under conditions where they estimate the concentration of the free ion. DGT (15) and gel integrated micro electrode (GIME) voltammetry $(16,17)$ were used to estimate the total concentration of labile and mobile species (known as dynamic). The relative performance of the techniques has been evaluated (10). Here, we compare results from this uniquely comprehensive set of measurements with speciation predictions made with humic ion binding model VI (WHAM) (18) and the NICA-Donnan model $(19,20)$.

\section{Methodology}

DGT and GIME $(5,10,16,17,21)$. In both cases, for a complex to be measured, it must diffuse through the gel at a reasonable rate (hence, be mobile) and dissociate within the time taken for it to pass through the diffusion layer (be labile) $(22,23)$. Based on concentrations in the reaction layer, a complex is considered to be sufficiently labile to be measured by a dynamic technique if the flux to the consuming surface attributed to dissociation of the complex, $J_{\text {kinn }}$, is of the order of magnitude of the maximum diffusive flux of complexed metal, $J_{\text {dif }}$ (24). This statement has been formulated into a lability criterion, $L=J_{\text {kin }} / J_{\text {dif }}(5)$. In practice, $J_{\text {kin }}$ is calculated from bulk concentrations and the ensuing approximate lability criterion comes to $L \$ 1$ when a complex is labile and to $L \& 1$ when it is nonlabile. The value of $L$ depends on the characteristics of the complex (diffusion coefficient, stability constant, $K$, dissociation rate constant) and the measurement time scale of the technique (5). 
Environ. Sci. Technol., 40 (6), 1942 -1949, 2006.

Calculation of $L$ for a technique used in natural waters is complicated by the unknown nature of the complexing ligands. We have assumed here, as for equilibrium models (see later), that the organic complexants are represented by fulvic acid. These heterogeneous ligands have binding sites with a distribution of $K$ values, resulting in a range of labilities for the bound metal that is affected by the extent of binding. We used a simplified approach to derive a value of $L$ for each metal, in each water studied, when measured by GIME and DGT under our conditions. A Table of values (S1) and details of the derivation are provided in the Supporting Information. The derivation assumed that the distribution of binding sites can be described by a Freundlich isotherm that incorporates a heterogeneity parameter (25). Due to uncertainties in the parameters, particularly rate constants, the values of $L$ given in Table S1 (Supporting Information) should be used as orders of magnitude.

The complexes are expected to be labile when measured by DGT ( $C u$ ( $L=380$ $1300), \mathrm{Pb}(\mathrm{L}=2730-5800)$, and $\mathrm{Cd}(\mathrm{L}=3270-13$ 840)), but marginally labile when measured by GIME ( $\mathrm{Cu}(\mathrm{L}=2-6), \mathrm{Pb}(\mathrm{L}=18-26)$, and $\mathrm{Cd}(\mathrm{L}=20-60))$. The metals bound to the strongest sites are expected to be nonlabile to GIME, while those bound to the weakest sites will be labile, consistent with the dissociation of metals from their complexes decreasing with increasing binding strength, according to the Eigen mechanism (26). A larger proportion of $\mathrm{Cu}$ is expected to be nonlabile, compared to $\mathrm{Pb}$ and $\mathrm{Cd}$, because its representative value of $\mathrm{L}$ is lower and at low concentrations of $\mathrm{Cu}$, most will be bound to stronger sites.

PLM (10-12). The PLM measurement can represent either the free metal concentration or the concentration of all dynamic species, depending on the permeability of the membrane as compared to the rate of transport in the aqueous (source) diffusion layer adjacent to the PLM surface. For the in situ measurements reported in this paper, using hollow fiber PLM (HFPLM), the permeability criterion, $\Pi$, values $(12,27)$ were in the range $0.005-0.02$ for $\mathrm{Cu}$, 0.01-0.2 for $\mathrm{Pb}$, and 0.0003 to 0.04 for $\mathrm{Cd}$ in all natural waters (see Supporting Information of ref 10), implying that in situ HFPLM measures the free metal ion. However, lipophilic complexes can also diffuse through the PLM (28) and contribute to the signal.

DMT. DMT uses a negatively charged, hydrophilic, cation exchange membrane to separate the solution to be investigated (donor) from an acceptor solution (13, 29). In these measurements, to improve detection limits, a humic acid with wellknown binding properties was added as ligand to the acceptor solution. After deployment, the total metal was measured in the acceptor solution, subtracting where ap propriate for metal added with the HA. Free metal ion concentrations were then derived using either the Donnan membrane equilibrium or ion transport kinetics. Further details are given in the Supporting Information of (10).

Field Sites and In Situ Deployment. Full details of the field sites, measurements, and protocols used during the fieldwork are provided in a companion paper (10). The input parameters for the speciation models are shown in Table S3 (Supporting Information). Model predictions of $\mathrm{Zn}$ speciation are not shown because of uncertainties in the $\mathrm{Zn}$ speciation measurements, but as filterable $\mathrm{Zn}$ was measured it was included as input data. Competitive binding to Zn had little effect, as reducing its concentration by a factor of 2 negligibly affected the speciation predictions of other metals, except for the free ion activity of $\mathrm{Cu}$, which decreased by up to $10 \%$. Filterable metal concentrations obtained by the host laboratories (Lancaster for Wyre and Dubendorf for Furtbach and Greifen) were used for each site, as they were the most comprehensive and 
Environ. Sci. Technol., 40 (6), 1942 -1949, 2006.

consistent data sets, with good precision and no evidence of contamination (see Tables S3 and S4c (Supporting Information) and Figure, S1 of ref 10).

Equilibrium Speciation Models. Binding of metal ions to humic substances (HS) is complicated by their variable charge, distribution of binding sites, variable stoichiometry of the reaction, and the competitive nature of the ion binding. Humic ion binding model VI $(18)$ and the NICA-Donnan model $(19,20)$ are two approaches to tackle this complicated problem. The NICA-Donnan model uses a bimodal, continuous distribution of affinities for protons and metal ions, whereas model VI is based on a discrete set of sites. The models are calibrated using published data on metal humic binding $(30,31)$.

Model VI was used in WHAM 6 (18) and the NICA-Donnan model (19) in Visual MINTEQ (VMINTEQ) (32). To ensure consistency, thermodynamic data (for inorganic metal complexes) from MINTEQA2 version 4, available at http://www.epa.gov/ceampubl/mmedia/minteq/SUPPLE1.PDF, was input into the databases of both programs. The default values for metal-humic binding in each program were used. The concentrations of HS were derived from the experimental DOC measurements: $50 \%$ of the DOC measured in the field samples was assumed to be HS (33), which were themselves assumed to be $50 \%$ carbon (Suwannee river fulvic acid is $52 \% \mathrm{C}$ ). The natural waters were modeled primarily with the HS being defined as $100 \%$ fulvic acid. The models were also run with the HS comprising a mixture of $90 \%$ fulvic and $10 \%$ humic acid, which may be more representative of the HS in natural waters(34).

The models were used to calculate the concentration of each species in solution using the filterable metal as the total concentration. With DMT and HFPLM (under the present חconditions), we generally expect to measure a free metal ion concentration that is directly comparable to the model prediction. Concentrations obtained from DGT and GIME are derived from the measured flux of dynamic species. Further calculations are required to enable model predictions of equilibrium concentrations to be compared to these dynamic measurements. Each metal species in solution, $x$, with concentration, $c_{x}$, has a diffusion coefficient, $D_{x}$, a diffusion layer thickness, $\varepsilon_{x}$, and contributes a flux, $J_{x}$, to the sensor surface of area $A$, assuming the sensor is a perfect sink and that $x$ is fully labile (eq 1 ).

$$
J_{x}=A c_{x} D_{x} \delta_{x}
$$

The total flux, $J$, measured at a sensor, is the sum of the fluxes of all labile species (eq 2).

$$
I=\sum I_{\mathrm{x}}
$$

In practice DGT and GIME are calibrated with simple inorganic solutions where the diffusion coefficient is $D_{M}$ and the diffusion layer thickness is $\boldsymbol{\Lambda}_{M}$. The concentration of dynamic species that is measured, $c_{\mathrm{dyn}}$, is derived from $J$ using eq 3.

$$
I=A c^{\mathrm{d} \mathrm{H}^{\mathrm{B}}} D_{M} / \Lambda_{\mathrm{M}}
$$

When all species are fully labile, $c^{\text {dyn }}$ has its maximum value, $c^{\text {dyn }}{ }_{\text {max }}$ that can be derived by combining eqs $1-3$ to give eq 4 .

$$
c_{\max }=\sum c_{z} D_{\mathrm{x}} \Delta_{M} / D_{M} \Lambda_{k}
$$

We assumed that diffusion coefficients were only significantly different from that of the free metal ion for complexes with fulvic acid (FA) or humic acid (HA) and that diffusion layer thicknesses were the same for complexes and free metal ions. Diffusion coefficients of fulvic acids are typically $20 \%$ of that of the free metal ion 
Environ. Sci. Technol., 40 (6), 1942 -1949, 2006.

(35). If only FA is present, a good approximation of the maximum dynamic concentration would be given by eq 5 .

$$
{ }^{\text {Byn }}{ }_{\max }=\sum \text { inorganic metal - }
$$

0.2 (metal-FA complexes) (5)

In the discussion, $C^{\mathrm{dyn}}{ }_{\max }$ is compared to concentrations measured by DGT and GIME.

\section{Results and Discussion}

Softwater Modeling. There are several possible model predictions, depending on assumptions made on the amount and precise form of HS and the presence or absence of colloidal metal oxides. More than $99 \%$ of the filterable $\mathrm{Cu}$ and $\mathrm{Pb}$ in the river Wyre was predicted to be bound to FA when WHAM 6, with the HS input as $100 \% \mathrm{FA}$, was used to calculate the speciation (Figure 1). Smaller fractions of the $\mathrm{Cd}(66 \%)$ and $\mathrm{Ni}(36 \%)$ were predicted to be bound to FA. Virtually all the $\mathrm{Cd}$ and $\mathrm{Ni}$ not bound to FA was predicted to be present as the free metal ion.

Assuming that a fraction (10\%) of the total HS in the model was HA did not have a significant $(<1 \%)$ effect on the net concentration of metal bound to HS (both FA and $\mathrm{HA}$ ). Modeling the same system using VMINTEQ produced similar results for $\mathrm{Cu}$ and $\mathrm{Pb}$ (Figure 1), but the proportion of $\mathrm{Cd}$ and $\mathrm{Ni}$ bound to $\mathrm{HS}$ increased ( $\mathrm{Cd}$ $97 \%$, Ni $50 \%)$. Increased metal ion binding to HS with the NICA-Donnan model has been reported previously (29). 
Environ. Sci. Technol., 40 (6), 1942 -1949, 2006.
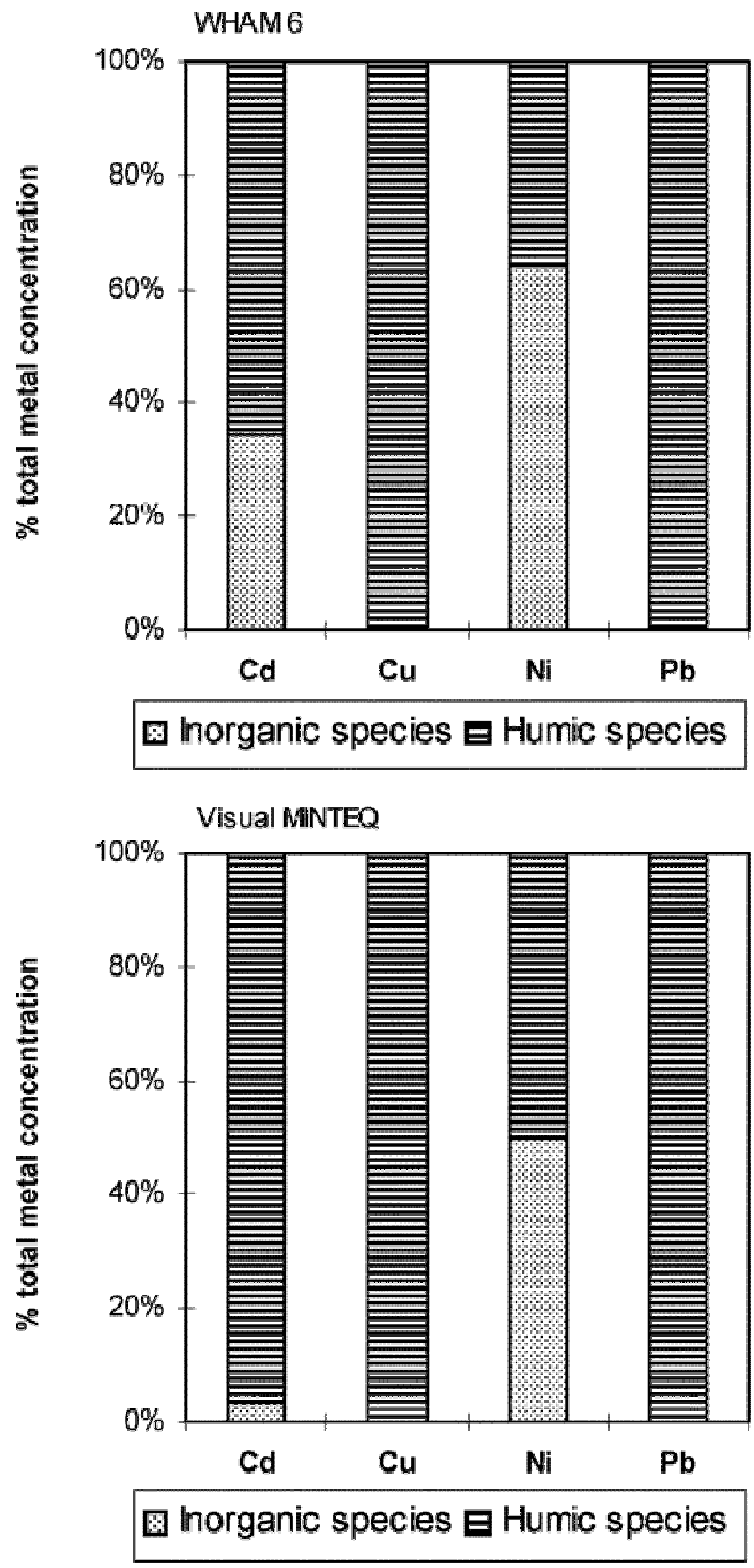

Figure 1 River Wyre speciation modeled with humic substances input as $100 \%$ fulvic acid.

$\mathrm{Fe}, \mathrm{Al}$, and $\mathrm{Mn}$ may influence the speciation of $\mathrm{Cu}, \mathrm{Pb}, \mathrm{Cd}$, and $\mathrm{Ni}$, either by being present as colloidal oxides or by competing for the fulvic and humic acids. The dissolved Fe concentration of $5.2 \mathrm{\mu mol} \mathrm{I}^{-1}$, was assumed to be present as Fe(III). WHAM 6 predicted it to be present as $25 \% \mathrm{Fe}-\mathrm{FA}$ and $75 \% \mathrm{Fe}(\mathrm{OH})_{3}(\mathrm{aq})$, with the 
Environ. Sci. Technol., 40 (6), 1942 -1949, 2006.

system oversaturated (based on ferrihydrite from the MINTEQA2 database).

Visual MINTEQ, however, predicted that $>99.9 \%$ of the Fe was present as Fe-FA species, and with unsaturation for $\mathrm{Fe}(\mathrm{OH})_{3(\mathrm{~s})}$. Such differences are not unexpected, given the sparse available data on binding of iron to HS (30). Using the WHAM 6 default parameters for the adsorption of trace metals to iron oxides, with $\mathrm{Fe}$ input as colloidal iron oxide rather than dissolved $\mathrm{Fe}, \mathrm{Pb}$ was the only appreciable colloidal trace metal, with $35 \%$ present bound to colloidal iron. The fraction of $\mathrm{Cd}$ and $\mathrm{Ni}$ present as metal-humic species increased (Figure 2), due to the removal of $\mathrm{Fe}$ as a dissolved metal that competes for HS binding sites.

Defining the HS in the model as all FA or a mixture of FA and HA did not affect the overall humic binding. When Fe was introduced as colloidal iron oxide in the VMINTEQ program (using the default trace metal adsorption values), both $\mathrm{Ni}$ and $\mathrm{Pb}$ were affected, with 6 and $7 \%$ of the metals, respectively, being bound to colloidal iron oxide. In this case adding $\mathrm{HA}$ to the model did have an effect, with the concentration of $\mathrm{Pb}$ present as colloidal bound species increasing to $14 \%$ of the total $\mathrm{Pb}$. 
Environ. Sci. Technol., 40 (6), 1942 -1949, 2006.

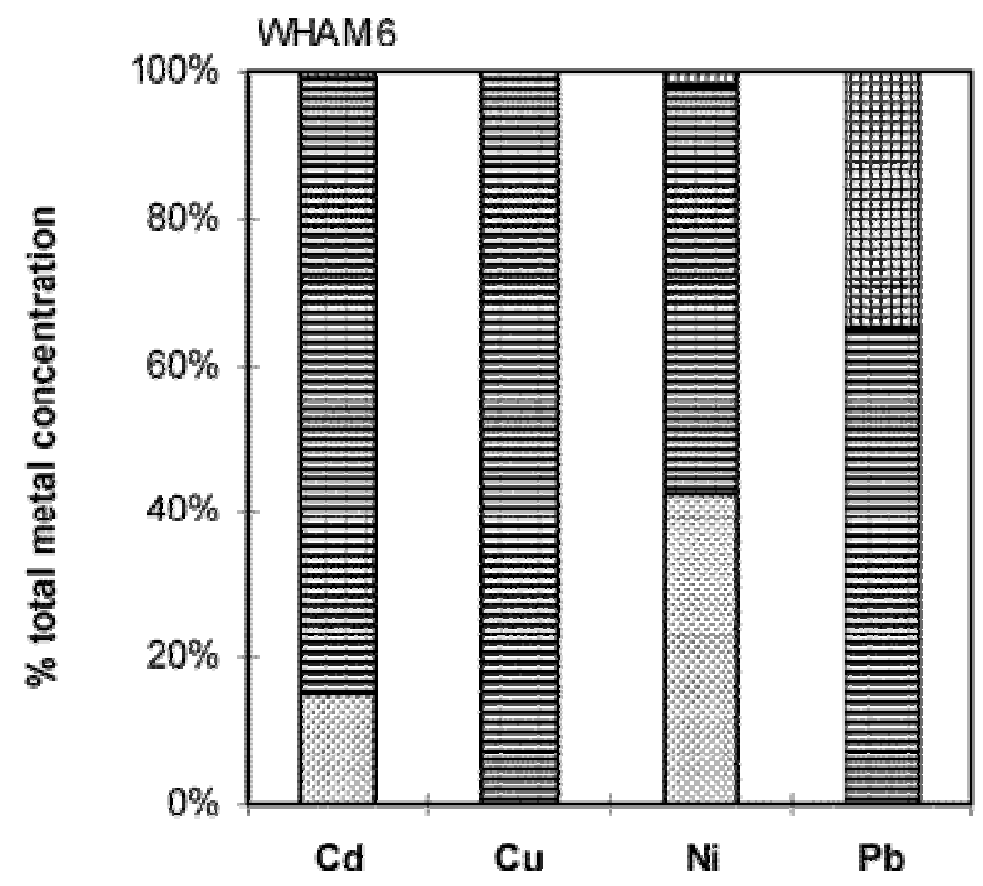

$\square$ Inorganic species $\mathbf{E}$ Humic species $\mathbf{t}$ Fe colloid species

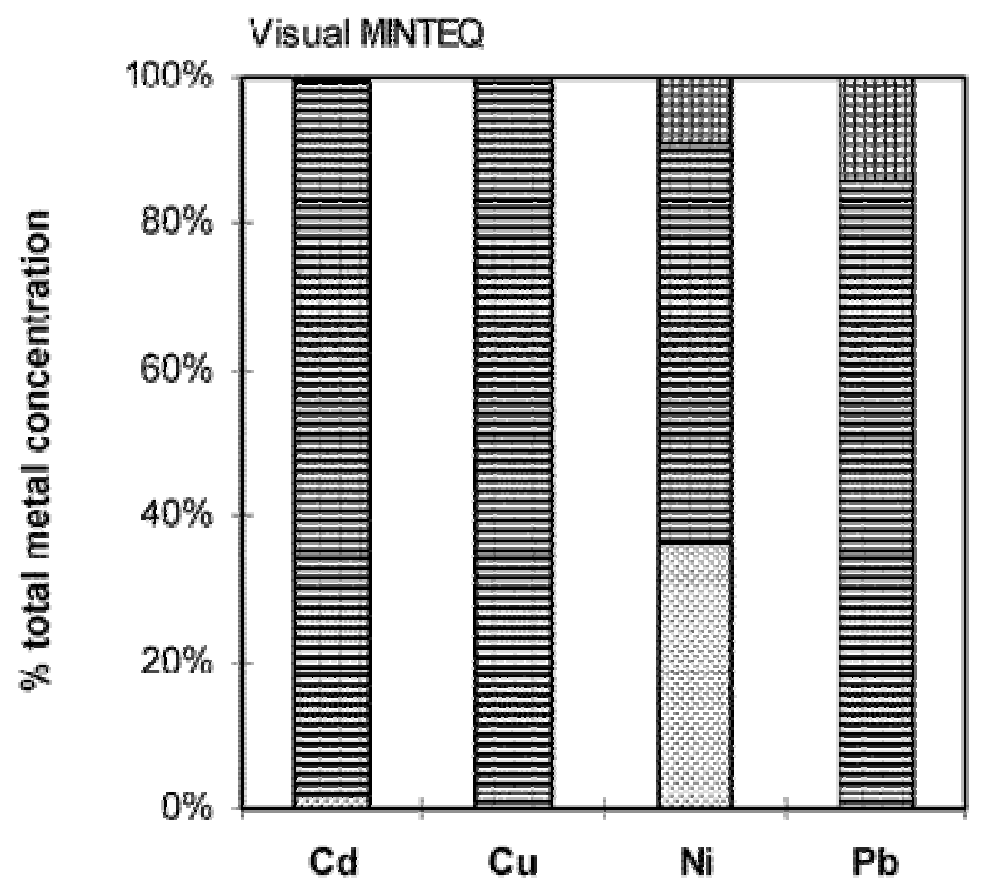

⿴囗大 Inorganic species $\mathrm{E}$ Humic species $⿴ 囗 十$ Fe colloid species

Figure 2 River Wyre speciation modeled with Fe input as colloidal $\mathrm{Fe}(\mathrm{OH})_{3}$ and humic substances input as $90 \%$ fulvic acid and $10 \%$ humic acid. 
Environ. Sci. Technol., 40 (6), 1942 -1949, 2006.

$\mathrm{Al}$ and $\mathrm{Mn}$ can be present in natural waters as colloidal oxides. As they can bind trace metals strongly, small amounts may appreciably affect trace metal speciation. The filterable concentration was close to saturation as $\mathrm{Al}(\mathrm{OH})_{3}$. DGT measured $41 \%$ of the total, filtered, Al concentration. When WHAM 6 was used with $50 \%$ of the measured Al present as a colloid, there was no change in the speciation. The Mn concentration measured by DGT was $104 \%$ of that measured by ICP-MS, indicating that it was not present in a colloidal form. When WHAM 6 was rerun with $10 \%$ of the filterable $\mathrm{Mn}$ defined as a colloid, there was no difference in the trace metal speciation, suggesting that $\mathrm{Mn}$ oxides can be discounted.

Hardwater Modeling. The most striking difference between model outputs for soft and hard waters (Figures 1-4) was that the free metal ions dominated the inorganic species in the softwater, while both free metal ions and carbonate species were important in hard waters. Both programs, with HS defined entirely as fulvic acid, predicted that $>99 \%$ of the $\mathrm{Cu}$ and $\mathrm{Pb}$ were present as metalhumic species in surface water in Lake Greifen. For $\mathrm{Cd}$ and $\mathrm{Ni}$ there was a smaller proportion of metal-humic species (Cd 50\%, Ni 12\% with WHAM 6 and Cd 93\%, Ni 53\% with vMINTEQ) and a corresponding larger proportion of free metal and carbonate species. The dominant carbonate species were $\mathrm{CdCO}_{3}{ }^{\circ}(15 \%$ with WHAM $6,1.4 \%$ with vMINTEQ) and $\mathrm{NiCO}_{3}{ }^{\circ}$ (40\% with WHAM 6 and $27 \%$ with VMINTEQ). Remodeling the system using WHAM 6 with the HS input altered to include HA (10 and $20 \%$ of the total HS concentration) did not substantially alter the total concentration of metal-humic species. The largest effect was for $\mathrm{Cd}$ with total $\mathrm{Cd}-\mathrm{HS}$ species increasing from 50 to $69 \%$ of the total Cd concentration. 
Environ. Sci. Technol., 40 (6), 1942 -1949, 2006.

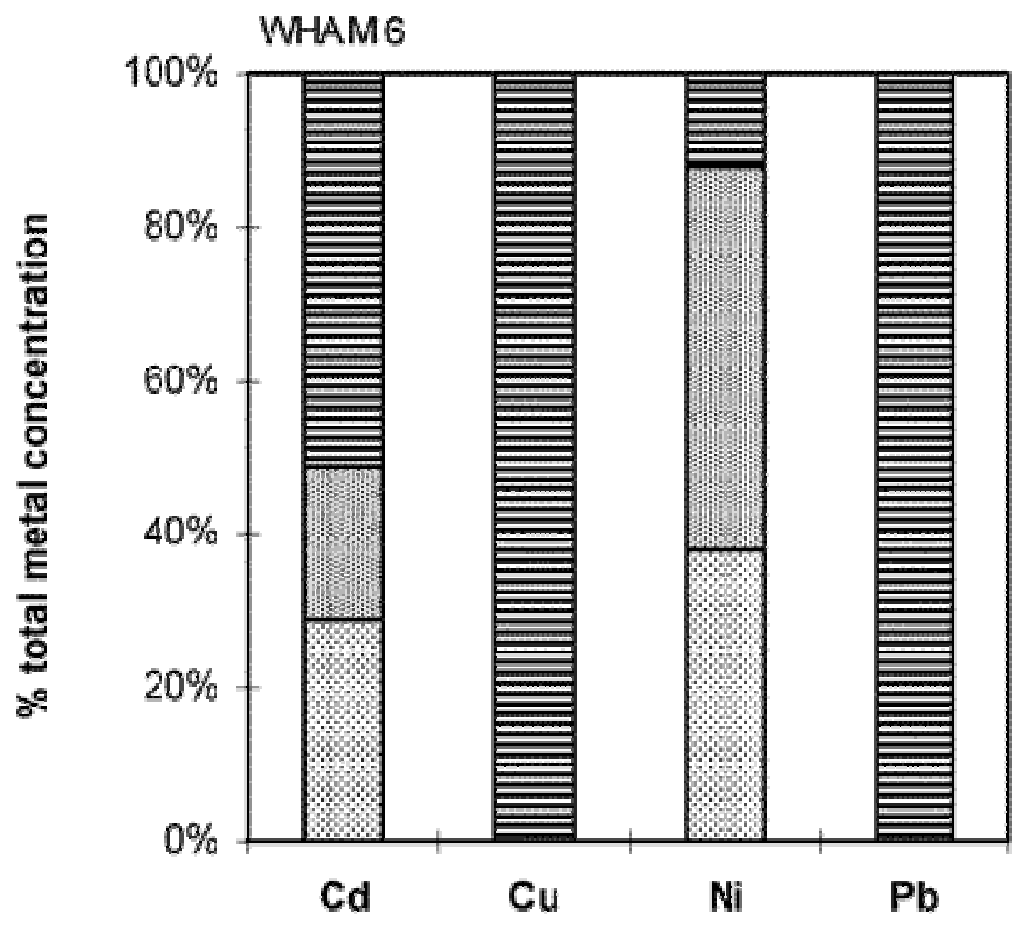

圆 $\mathrm{M} 2+$ species 图 Carbonate species $\mathrm{日}$ Humic species

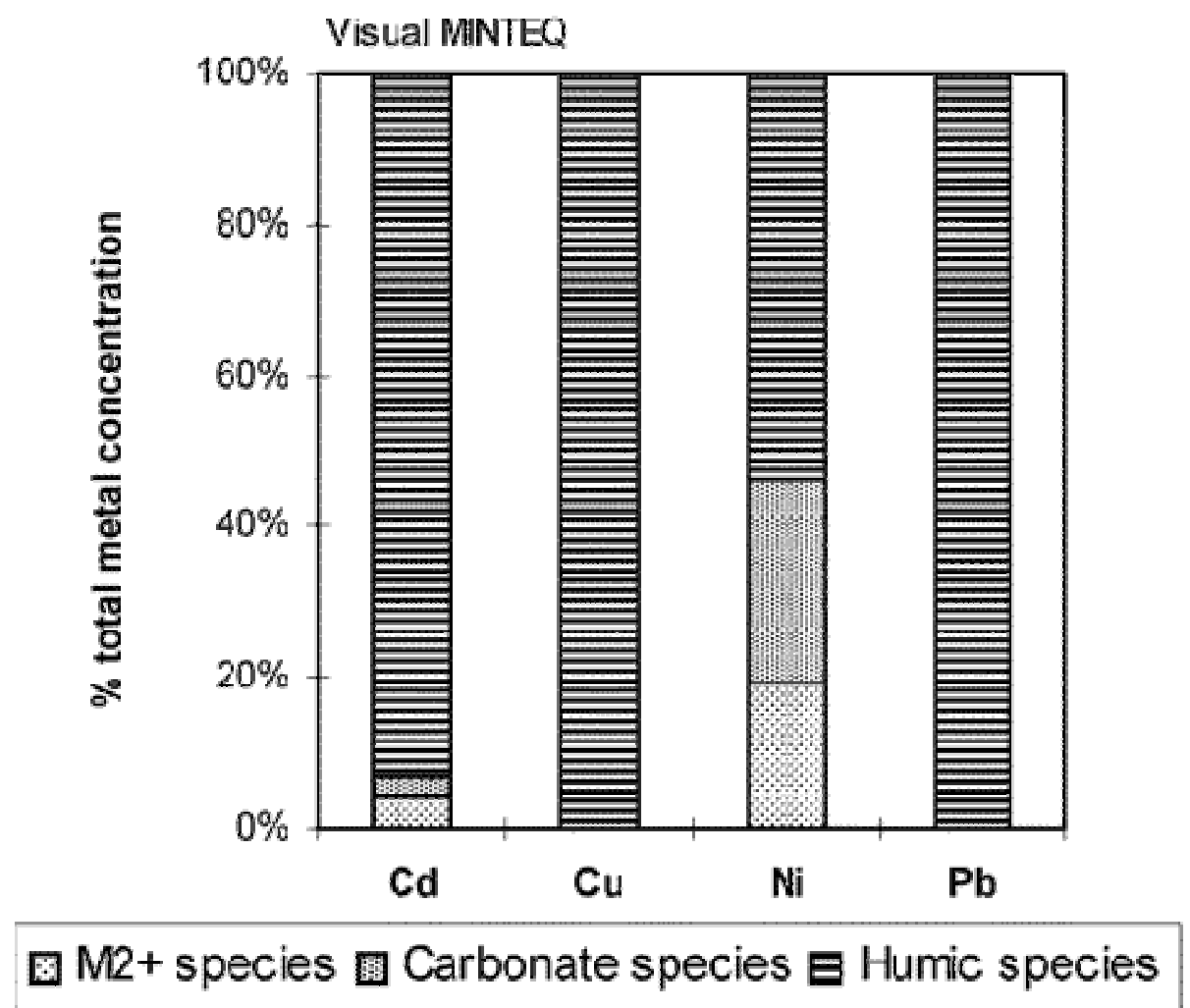

Figure 3 Lake Greifen speciation modeled with humic substances input as $100 \%$ fulvic acid. 
Environ. Sci. Technol., 40 (6), 1942 -1949, 2006.

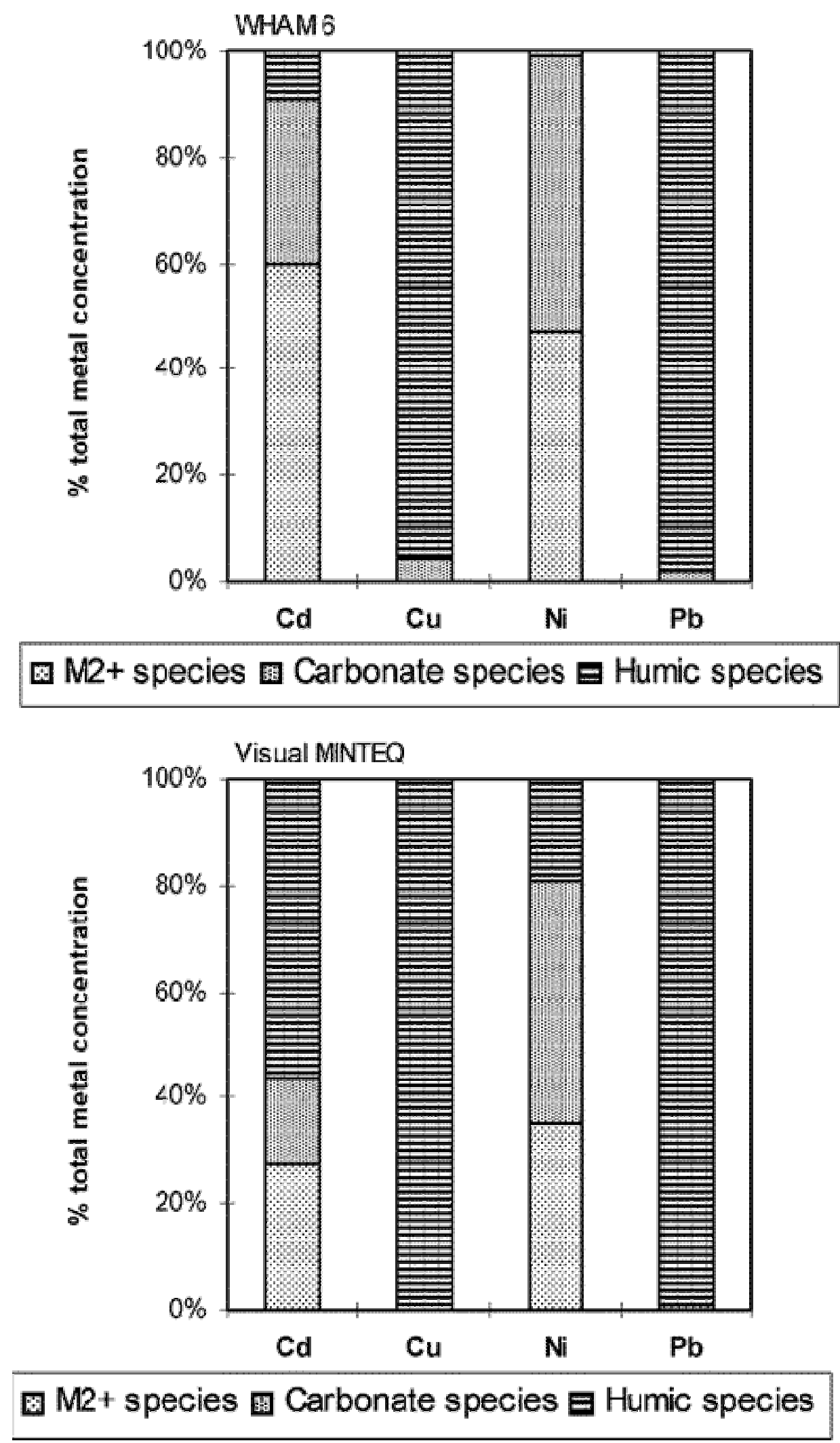

Figure 4 Furtbach stream speciation modeled with humic substances input as $100 \%$ fulvic acid. 
Environ. Sci. Technol., 40 (6), 1942 -1949, 2006.

The Furtbach stream, had a higher concentration of $\mathrm{Ca}$ and carbonate and a lower DOC concentration than Lake Greifen. As for Lake Greifen, metal-humic species were predicted to dominate the $\mathrm{Cu}$ and $\mathrm{Pb}$ speciation (Cu 96\%, Pb 98\% using WHAM 6 and $\mathrm{Cu}>99 \%, \mathrm{~Pb} 98 \%$ using VMINTEQ). Free metal ion and carbonate species were more important for $\mathrm{Cd}$ and $\mathrm{Ni}$ (total inorganic species $\mathrm{Cd} 91 \%, \mathrm{Ni}$ $99 \%$ using WHAM 6 and Cd 45\%, Ni 81\% using VMINTEQ). Adding HA to the models had little effect on the total concentrations of metal-humic species for either hardwater.

Generally the predictions of the two models are consistent, but VMINTEQ predicted higher proportions of metal-humic species for $\mathrm{Cd}$ and Ni than WHAM 6. Calculations with inputs of $90 \% \mathrm{FA}, 10 \% \mathrm{HA}$, and $100 \% \mathrm{Fe}$ as colloids, that are considered to be most realistic, are used in the discussion of softwater data. Iron was not measured in the hardwaters, but is expected to be at smaller concentrations than in the River Wyre and thus to be less important as a colloid affecting trace metal speciation.

Measurements and Predictions in Synthetic Softwater. Solutions were prepared with a similar (inorganic) composi tion to that of the river Wyre, but different amounts of added FA. With $5 \mathrm{mg} \mathrm{I}^{-1} \mathrm{FA}$, DGT measured $26 \%$ of the total $\mathrm{Cu}$ concentration in solution and $29 \%$ of the $\mathrm{Pb}$. With $20 \mathrm{mg} \mathrm{l}^{-1} \mathrm{FA}$, DGT measured $16 \% \mathrm{Cu}$ and $16 \% \mathrm{~Pb}$. If the metal was completely in the form of metal-fulvic species, as predicted by both WHAM 6 and VMINTEQ, and assuming that these species are labile, the DGT measured concentration would be ca. $20 \%$ of the total metal concentration in solution (as explained above after eq 4 ). The reasonable agreement between the DGT measurement and predictions, both here and elsewhere $(36,37)$, suggests that the metal fulvic species are fully DGT labile, as predicted by lability calculations (Table S1, Supporting Information).

In-field Deployments. At all three field sites DGT and GIME measured substantially higher concentrations of metals than HFPLM and DMT (10) consistent with the features of these techniques. Even with moderate lability, the concentration of dynamic species measured by DGT and GIME would be expected to be substantially higher than the concentration of free ions measured by both HFPLM and DMT.

Measurements and Predictions for Dynamic Techniques-Softwater. In the river Wyre, Cu concentrations measured by DGT and GIME (Table S4, Supporting Information) were 13 and $6 \%$, respectively, of the total (filtered) metal, $[\mathrm{M}]_{\mathrm{tf}}$, measured by ICP-MS (Figure 5a). Based on model predictions of near $100 \%$ complexation of $\mathrm{Cu}$, the maximum dynamic metal should be ca. $20 \%$ of $[\mathrm{Cu}]_{\mathrm{tf}}$. The reasonable agreement between model predictions and DGT measurements is consistent with most bound metal being fully DGT labile, as expected for $L=$ 1300 . The lower value for GIME suggests some kinetic limitation, consistent with $\mathrm{L}=6$. 

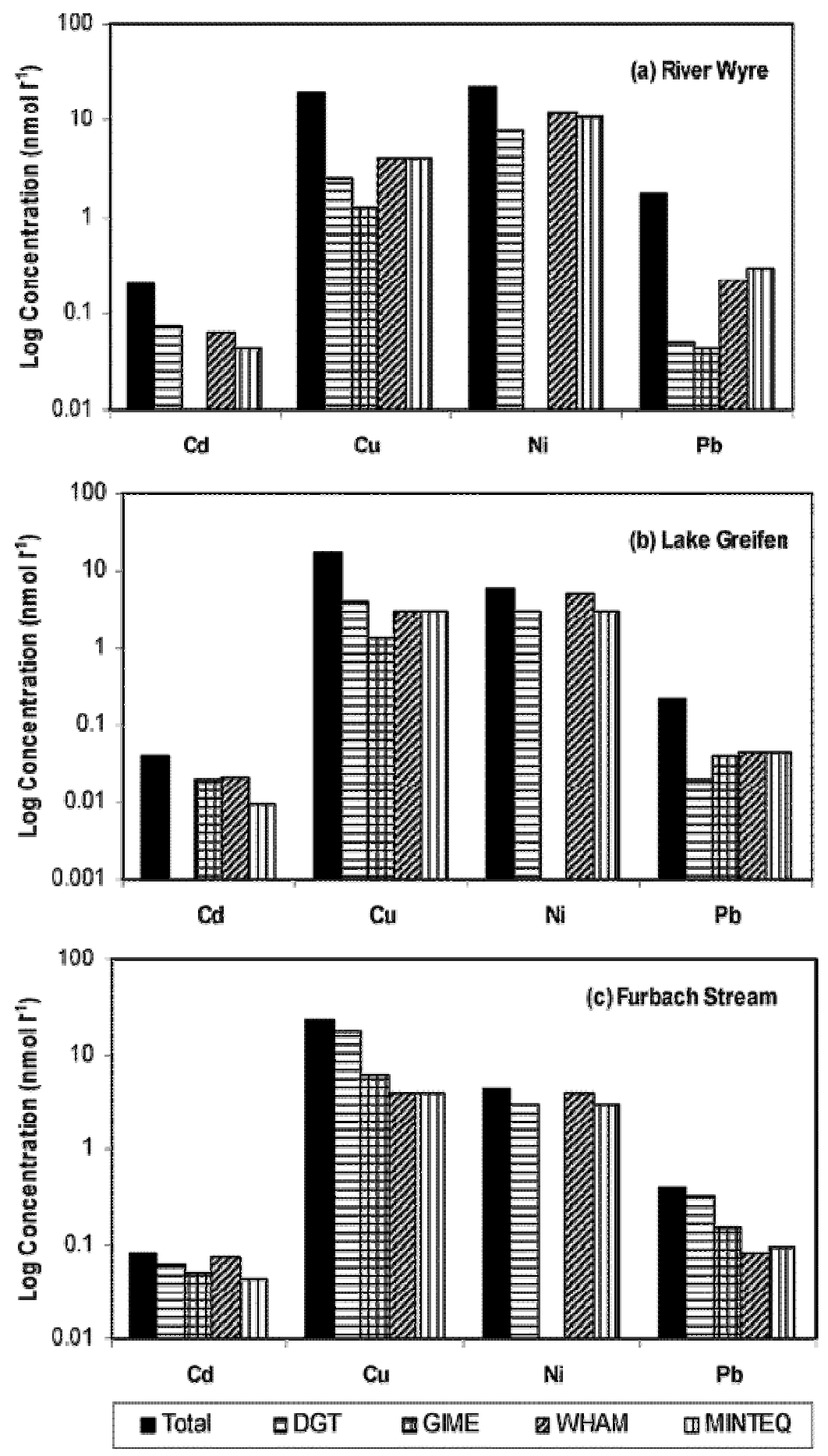

Figure 5 Concentrations of trace metals measured in situ in the three waters using two speciation techniques (diffusive gradients in thin-films and gel integrated microelectrode), compared to concentrations measured in samples filtered on site (total) and predictions of measured species assuming complete lability ( ${ }^{\text {dyn }}$ max $)$ using the WHAM 6 and Visual MINTEQ models. Reproducibility, based on measurements of replicate samples, was within $20 \%$ for GIME and $12 \%$ for DGT. HS were $90 \%$ FA and 10\% HA. For the River Wyre, the measured iron was assumed to be present as colloidal oxides. 
Environ. Sci. Technol., 40 (6), 1942 -1949, 2006.

The $\mathrm{Pb}$ concentration measured by both DGT and GIME was only a small fraction (DGT $3 \%$, GIME $2 \%$ ) of $[\mathrm{Pb}]_{\mathrm{tf}}$. A fraction of at least $20 \%$ would be expected if $\mathrm{Pb}$ was present predominantly as humic complexes, as $\mathrm{Pb}-\mathrm{FA}$ species have been shown to be labile to DGT at pH 6 (35). Although at the higher pH of this work, there may be humic sites that bind $\mathrm{Pb}$ so strongly that it is effectively inert, lability calculations suggest that this is not the case (Table S1, Supporting Information). These results suggest that most of the $\mathrm{Pb}$ is in a nonlabile or nonmobile form. Colloidal species could be present in the prevailing high flow conditions when sampling took place. They would not be measured by DGT or GIME, due to their lower diffusion coefficients or incapacity to permeate the gel. When Fe was assumed to be colloidal, 14\% (VMINTEQ) and 35\% (WHAM 6) of the $\mathrm{Pb}$ was predicted to be present as $\mathrm{Pb}-\mathrm{Fe}$ colloids. These model predictions may underestimate the binding of $\mathrm{Pb}$ to iron oxide, or there may be sufficient other colloids present (e.g., of $\mathrm{Mn}, \mathrm{Al}$, or $\mathrm{Si}$ ) to account for a greater proportion of $\mathrm{Pb}$ being present in colloidal form.

The Cd concentration measured by DGT was similar to the $c^{d y n}{ }_{\max }$ predicted by WHAM 6 when Fe was input into the model as a colloid (Figure $5 \mathrm{a}$ ). For the equivalent VMINTEQ model, $c^{\text {dyn }}{ }_{\max }$ was lower because this model predicted a higher proportion of Cd-humic species.

The Ni concentrations measured by DGT were lower than the model predictions. Dissociation kinetics of $\mathrm{Ni}$ are known to be slow compared to other metals (23). Therefore, even though binding to humic substances is much weaker than for $\mathrm{Cu}$, some kinetic limitation can be expected. It may be that DGT is simply measuring inorganic species in this case.

Measurements and Predictions for Dynamic Techniques-hardwaters. Speciation measurements carried out in Lake Greifen followed the same general trend as seen in the river Wyre. The maximum dynamic concentration of $\mathrm{Cu}$ predicted by both speciation programs was very close to the concentration measured by DGT. The lower value for GIME is consistent with borderline lability $(L=2)$.

DGT and GIME measured a larger fraction of $[\mathrm{Pb}]_{\mathrm{tf}}$ in Lake Greifen than in the river Wyre, where DOC was higher (Table S3, Supporting Information). The $\mathrm{Ni}$ concentration measured by DGT was the same as $C^{\text {dyn }}{ }_{\max }$ predicted by VMINTEQ and close to that predicted by WHAM 6 . The maximum dynamic concentration of Cd predicted by WHAM 6 agreed with the GIME measurement, reflecting its high L value of 32 .

In the Furtbach stream the $\mathrm{Cu}, \mathrm{Pb}, \mathrm{Cd}$, and $\mathrm{Ni}$ concentrations measured by DGT and GIME (Figure 6a) are larger fractions of $[\mathrm{M}]_{\mathrm{tf}}$ than that measured in the river Wyre and Lake Greifen. According to model predictions, even with the lower dissolved organic carbon, there should be $>90 \%$ metal humic species for $\mathrm{Cu}$ and $\mathrm{Pb}$. Therefore, a lower proportion of dynamic metal would have been expected, suggesting that binding by HS is not as dominant as predicted. The very low concentrations involved preclude meaningful speculation on the difference between the concentration measured by DGT and GIME for $\mathrm{Cu}$ and $\mathrm{Pb}$. For $\mathrm{Cd}$ the predicted $c^{\mathrm{dyn}}$ max was just above (WHAM 6) and below (VMINTEQ) the DGT and GIME results, consistent with full lability. Ni measured by DGT agreed well with $C^{\text {dyn }}{ }_{\text {max }}$ predicted by VMINTEQ, which was only a little lower than the corresponding prediction using WHAM 6. 

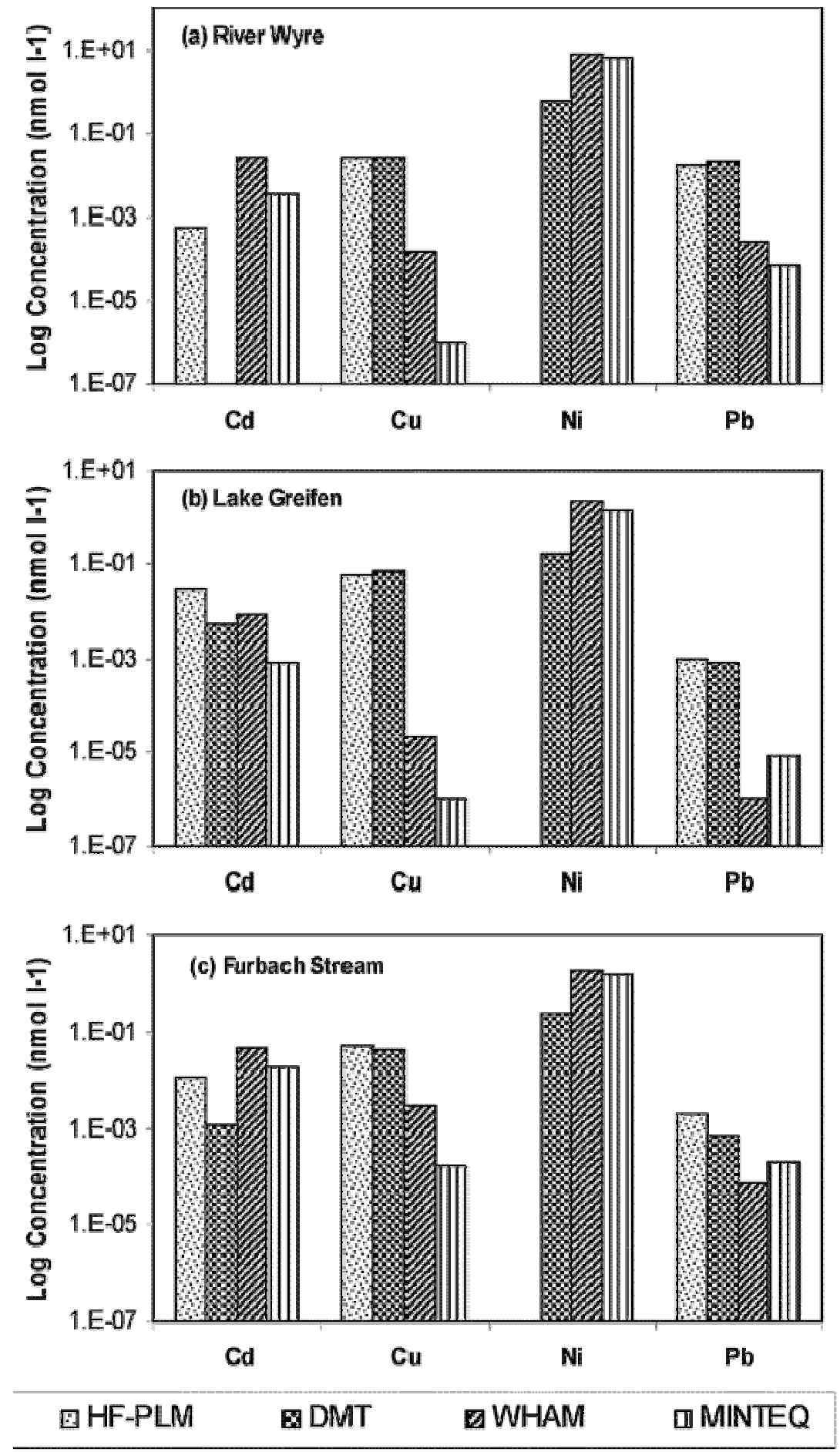

Figure 6 Concentrations of free ions measured by two speciation techniques (hollow fiber permeable liquid membrane and Donnan membrane technique), compared to concentrations predicted by two speciation models (WHAM 6 and Visual MINTEQ). Reproduc ibility, based on measurements of replicate samples, was within $15 \%$ for DMT and $20 \%$ for HF-PLM, except for Pb by HF-PLM, which was $50 \%$. 
Environ. Sci. Technol., 40 (6), 1942 -1949, 2006.

Measured and Predicted Free Ion Concentrations. Free ion concentrations were calculated assuming that HS comprised $90 \%$ FA and $10 \% \mathrm{HA}$. For the river Wyre, the primary calculations assumed that Fe was present as colloids for consistency with calculations that correspond best to the dynamic measurements. Measurements of free ion concentrations of both $\mathrm{Cu}$ and $\mathrm{Pb}$ by DMT and HF-PLM agreed well (Figure 6 and Table S5, Supporting Information). More apparent $\mathrm{Cd}^{2+}$ is found by HFPLM than DMT in both Furtbach stream and Lake Greifen. This can be attributed to the appreciable concentrations of neutral (PLM-membrane permeable) $\mathrm{CdCO}_{3}$ in Lake Greifen (1.4\% VMINTEQ, $15 \%$ WHAM 6) and Furtbach (14\% vMINTEQ, $29 \%$ WHAM 6$)$.

HFPLM and DMT results for $\mathrm{Cd}^{2+}$ are similar for the River Wyre, where $\mathrm{CdCO}_{3}$ "is negligible $(<1 \%)$. WHAM 6 generally predicted more free metal ions than VMINTEQ, most markedly for $\mathrm{Cu}$. Agreement between predictions and measurements of $\mathrm{Cd}^{2+}$ were usually within an order of magnitude for at least one model and technique. The predictions for $\mathrm{Ni}^{2+}$ were an order of magnitude higher than the DMT measurements. For WHAM 6, the difference was less when the default database was used, but changing the database had little effect for the other metals. The two models predicted similar $\mathrm{Pb}^{2+}$, but they were lower than the measured values by about 1 (Wyre and Furtbach) and 3 orders of magnitude (Greifen). Visual MINTEQ predictions of $\mathrm{Cu}^{2+}$ were 2-5 orders of magnitude less than measured values, while the higher $\mathrm{Cu}^{2+}$ concentrations predicted by WHAM 6 were still 1-3 orders of magnitude less than the measured values.

There is no conflict in obtaining reasonable agreement for $\mathrm{Cu}$ and $\mathrm{Pb}$ between measurements and predictions for the two dynamic techniques (except $\mathrm{Pb}$ in the Wyre), while poor agreement for free ion concentrations. Within measurement error, DGT and GIME may give the same value of maximum dynamic concentration, whether the proportion of HS complexes is 95 or $99.995 \%$, even though free ion concentrations will change by 3 orders of magnitude. There are several possible explanations for the poor agreement between measured and modeled values of $\mathrm{Cu}^{2+}$ and $\mathrm{Pb}^{2+}$.

1. Competitive binding with Fe(III) in solution is known to affect markedly the extent of $\mathrm{Cu}$ complexation by HS, due to competition for the small proportion of very strong binding sites (38). When the calculation was repeated for the river Wyre, assuming that all measured Fe was present in solution as Fe(III) (vastly supersaturated), the concentration of both $\mathrm{Cu}^{2+}$ and $\mathrm{Pb}^{2+}$ calculated using WHAM 6 and VMINTEQ increased substantially (Table S5, Supporting Information). However, calculations using WHAM 6 for all these waters, based on the assumption that they were saturated with amorphous Fe hydroxide ( $\log K_{\mathrm{so}, 25}=$ 4.0) (38), suggested that very low concentrations of Fe would be present as solution species and complexed to HS. Consequently free ion concentrations of trace metals were little different to those shown in Figure 6 that were calculated assuming that Fe was present as colloidal oxides. Tipping et al. (38) found similar results at high $\mathrm{pH}$.

2. The generic constants used in the modeling represent an average of metal humic binding parameters determined in laboratory experiments with extracted HS. The behavior of the humic molecules in water may be more wide ranging and some assumptions, such as $50 \%$ of DOC as humic, may be inappropriate. Prediction of free ion activities is an extreme test of the models, as it effectively involves extrapolation of laboratory measured data to very low concentrations.

3. The comparison between laboratories shows that uncertainties in the $[\mathrm{M}]_{\mathrm{tf}}$ used as model inputs is well within a factor of 2 and, therefore, cannot account for the 
Environ. Sci. Technol., 40 (6), 1942 -1949, 2006.

order of magnitude differences observed in calculated and modeled free ion activities.

4. The consideration in both models of binding to colloidal Fe oxides and heterogeneous binding to HS is likely to simplify considerably the true situation, where, for example, the binding properties and stability of Fe colloids may be modified by HS.

5. There may be problems with the measurements by HFPLM and DMT, e.g., measurement of neutral species by PLM., or transport of neutral or positive metal complexes across the DMT membrane (13), but recent work suggests DMT problems are unlikely (14). Moreover, agreement between the techniques is remarkably good in the absence of lipophilic complexes, especially considering that they have been undertaken by a different group of workers at concentrations of 1-100 pmol I-1. $\mathrm{Cu}^{2+}$ has been measured previously in Lake Greifen (39) and Furtbach (40) using competitive ligand exchange adsorptive stripping voltam metry (CLE-AdSV in the laboratory, yielding $\mathrm{Cu}^{2+}$ concentrations of $10^{-16}-10^{-14}$ and $10^{-14}-10^{-12} \mathrm{M}$, respectively, i.e., of the same order of magnitude as the model predictions or lower. However, incomplete equilibration with the competing ligand, due to slow rates of complex dissociation, may lead to an overestimation of binding strengths and underestimation of free ion activities by CLE-AdSV (41).

6. As both DMT and HFPLM preconcentrate metal while deployed in situ, they should not be prone to contamination; additionally, it is unlikely that similar contamination would be obtained for both techniques. However, although clean room procedures were adopted by both laboratories, contamination during handling after deployment cannot be excluded entirely. Rigorous corrections were made for metals in the introduced HA (see ref 42 for details).

The results from this work suggest that WHAM 6, incorporating humic ion binding model VI, and visual MINTEQ, incorporating NICA Donnan, can predict the distribution of the dominant species of trace metals in freshwaters with reasonable accuracy. However, concentra tions of free ions, when they represent a very small fraction of total dissolved concentrations, as for $\mathrm{Cu}$ and $\mathrm{Pb}$, may be under-estimated by several orders of magnitude. These uncertainties are concerning, given the current importance ascribed to the free ion in models of biological uptake. There is an urgent need to perform further accurate speciation measurements in natural waters where the total dissolved concentrations of all relevant species can be accurately measured, to test further both models and methods to identify the causes of the discrepancy.

\section{Acknowledgment}

This work was performed within the framework of the BIOSPEC project funded by the European Commission's RTD Program "Preserving the Ecosystem" (Key Action Sustainable Management and Quality of Water), under contract EVK1-CT-200100086.

\section{Supporting Information Available}

Further details, tables, and calculations. This material is available free of charge via the Internet at http://pubs.acs.org.

* Corresponding author. 
Environ. Sci. Technol., 40 (6), 1942 -1949, 2006.

fUniversity of Lancaster.

ҒEAWAG, Swiss Federal Institute for Environmental Science and Technology.

ŚUniversity of Geneva, Section de Chimie - Sciences II.

LRijksinstituut voor Volksgezondheid en Milieu.

Universitat de Lleida.

$\rtimes$ Department of Soil Quality, Wageningen University.

OLaboratory of Physical Chemistry and Colloid Science, Wageningen University. \# University of Southern Denmark. 
Environ. Sci. Technol., 40 (6), 1942 -1949, 2006.

\section{References}

1. Bryan, S. E.; Tipping, E.; Hamilton-Taylor, J. Comparison of measured and modelled copper binding by natural organic matter in freshwater. Comp. Biochem. Physiol. C 2002, 133, 37-49.

2. Dwane, G. C.; Tipping, E. Testing a humic speciation model by titration of copper-amended natural waters. Environ. Int. 1998, 24, 609-616.

3. Christensen, J. B.; Christensen, T. H. The effect of pH on the complexation of $\mathrm{Cd}, \mathrm{Ni}$ and $\mathrm{Zn}$ by dissolved organic carbon from leachate-polluted groundwater. Water. Res. 2000, 34, 3743-3754.

4. Oste, L. A.; Temminghoff, E. J. M.; Lexmond, T. M.; van Riemsdijk W. H. Measuring and modelling zinc and cadmium binding by humic acid. Anal. Chem. 2002, 74, 856-862.

5. van Leeuwen, H. P.; Town, R. M.; Buffle, J.; Cleven, R. F. M. J.; Davison, W.; Puy, W. H.; Sigg, L. Dynamic speciation analysis and bioavailability of metals in aquatic systems. Environ. Sci. Technol., 2005 39(22); 8545-8556.

6. USEPA 2003. 2003 Draft Update of Ambient Water Quality Criteria for Copper, EPA 822-R-03-026; U.S. Environmental Protection Agency: Washington DC; 2003;

http://www.epa.gov/waterscience/criteria/copper/pdf/master.pdf.

7. McGeer, A. physiologically based biotic ligand model for predicting the acute toxicity of waterborne silver to rainbow trout in freshwaters. Environ. Sci. Technol. 2000, 34, 4199-4207.

8. DiToro, D. N.; Allen, H E.; Bergman, H. L.; Meyer, J. S.; Paquin, P. R.; Santore, R. C.. Biotic ligand model of the acute toxicity of metals. 1. Technical basis. Environ. Toxicol. Chem. 2001, 20, 23832396.

9. Buffle, J.; Horvai, G. In Situ Monitoring of Aquatic Systems, Chapter 11-17; John Wiley and Sons: Chichester, 2000

10. Sigg, L.; Black, F.; Buffle, J.; Cao, J.; Cleven, R. F. M. J.; Davison, W.; Galceran, J.; Gunkel, P.; Kalis, E. J. J.; Kistler, D.; Martin, M.; Noel, S.; Nur, Y.; Odzak, N.; Puy, J.; Van Riemsdijk, W. H.; Temminghoff, E. J. M.; Tercier-Waeber, M.-L.; Toepperwien, S.; Town, R. M.; Unsworth, E.; Warnken, K. W.; Weng, L. P.; Xue, H. Zhang, H.; Comparison of analytical techniques for dynamic trace metal speciation in natural freshwaters. Environ. Sci. Technol. 2006, 40, XXXX.

11. Parthasarathy, N.; Pelletier, M.; Buffle, J. Hollow fibre based supported liquid membrane: a novel analytical system for trace metal analysis. Anal. Chim. Acta 1997, 350, 183-195.

12. Buffle, J.; Parthasarathy, N.; Djane, N.-K.; Matthiasson, L. Permeation liquid membrane for field analysis and speciation of trace compounds in waters. In: In Situ Monitoring of Aquatic Systems, Chapter 10; John Wiley and Sons: Chichester, 2000; pp 407-493.

13. Temminghoff, E. J. M.; Plette, A. C. C.; van Eck, R. van Riemsdijk, W. H. Determination of the chemical speciation of trace metals in aqueous systems by the Wageningen donnan membrane technique. Anal. Chim. Acta 2000, 417, 149-157.

14. Weng, L. P.; Van Riemsdijk, W. H.; Temminghoff, E. J. M. Kinetic aspects of Donnan membrane technique for measuring the free ion concentration. Anal. Chem. 2005, 77, 2852-2861.

15. Davison, W.; Zhang, H. In situ speciation measurements of trace components in natural water using thin-film gels. Nature 1994, 367, 546-548.

16. Pei, J.; Tercier-Waeber, M.-L.; Buffle, J. Simultaneous deter mination and speciation of zinc, cadmium, lead and copper in natural water with minimum handling and artifacts, by voltammetry on a gel-integrated microelectrode array. Anal. Chem. 2000, 72, 161-171.

17. Buffle, J.; Tercier-Waebe, r M.-L. In situ voltammetry: concepts and practise for trace analysis and speciation. In In Situ Monitoring of Aquatic Systems, Chapter 9; John Wiley and Sons: Chichester, 2000; pp 279-405. 
Environ. Sci. Technol., 40 (6), 1942 -1949, 2006.

18. Tipping, E. Humic Ion Binding Model VI: An improved description of the interactions of protons and metal ions with humic substances. Aquat. Geochem. 1998, 4, 3-48.

19. Benedetti, M. F.; Milne, C. J.; Kinniburgh, D. G.; Van Riemsdijk, W. H.; Koopal, L. K. Metal ion binding to humic substances: Application of the nonideal competitive adsorption model. Environ. Sci. Technol. 1995, 29, 446-457.

20. Kinniburgh, D. G.; van Riemsdijk, W. H.; Koopal, L. K.; Borkevec, M.; Bennedetti, M. F. Ion binding to natural organic matter: competition, heterogeneity, stoichiometry and thermodynamic consistency. Colloids Surf. A 1999, 151, 147-166.

21. Zhang, H.; Davison, W. Performance characteristics of diffusion gradients in thin films for the in situ measurement of trace metals in aqueous solutions. Anal. Chem. 1995, 67, 3391-3400.

22. van Leeuwen H. P. Dynamic aspects of in situ speciation processes and techniques. In In situ monitoring of aquatic systems chemical analysis and speciation; Buffle J., Horvai G., Eds; John Wiley and Sons: Chichester, 2000.

23. Scally, S.; Davison, W.; Zhang H. In situ measurements of dissociation kinetics and labilities of metal complexes in solution using DGT. Environ. Sci. Technol. 2003, 37, 1379-1384.

24. Puy, J.; Cecília, J.; Galceran, J.; Town, R. M.; van Leeuwen, H. P. Voltammetric lability of multiligand complexes: the case of $M L_{2}$. J. Electroanal. Chem. 2004, 571, 121-132.

25. Town, R. M.; van Leeuwen, H. P. Dynamic speciation analysis of heterogeneous metal complexes with natural ligands by stripping chronopotentiometry at scanning deposition potential (SSCP). Aust. J. Chem. 2004, 57, 983-992.

26. Eigen, M.; Wilkins, R. G. The kinetics and mechanism of formation of metal complexes. In Mechanisms of Inorganic Reactions, Advances in Chemistry series number 49; Gould R. F. Ed.; American Chemical Society: Washington DC, 1965.

27. Salaun, P.; Buffle, J. Integrated microanalytical system coupling permeation liquid membrane and voltammetry for trace metal speciation. Theory and applications. Anal. Chem. 2004, 76, 31-39.

28. Parthasarathy, M.; Pelletier, M.; Buffle, J. Permeation liquid membranes for trace metal speciation in natural waters; transport of liposoluble Cu(II) complexes. J. Chromatog. A 2004, 1025, 33-40.

29. Weng, L. P.; Temminghoff, E. J. M.; Lofts, S.; Tipping, E. van Riemsdijk, W. H. Complexation with dissolved organic matter and solubility control of heavy metals in sandy soil. Environ. Sci. Technol. $2002,36,4804-4810$.

30. Milne, C. J.; Kinniburgh, D. G.; Tipping, E. Generic NICA-Donnan parameters for proton binding by humic substances. Environ. Sci. Technol. 2001, 35, 2049-2059.

31. Milne, C. J.; Kinniburgh, D. G.; van Riemsdijk, W. H.; Tipping, E. Generic NICA-Donnan parameters for metal-ion binding by humic substances. Environ. Sci. Technol. 2003, 37, 958-971.

32. Gustafsson, J. P. A Windows version of MINTEQA2;

http://www.Iwr.kth.se/English/OurSortware/vminteq/index.htm.

33. Martin-Mousset, B.; Croue, J. P.; Lefebvre, E.; Legube, B. Distribution and characterisation of dissolved organic carbon of surface waters. Water. Res. 1997, 31, 541-553.

34. Tipping, E. Cation binding by humic substances, Cambridge University Press: Cambridge, 2002.

35. Scally, S.; Davison, W.; Zhang H. Measurement of Pb complexation with organic ligands using DGT. Aust. J. Chem. 2004, 57, 925-930.

36. Zhang, H.; Davison, W. Direct in situ measurements of labile inorganic and organically bound metal species in synthetic solutions and natural waters using diffusive gradients in thin films. Anal. Chem. 2000, 72, 4447-4457. 
Environ. Sci. Technol., 40 (6), 1942 -1949, 2006.

37. Unsworth, E. R.; Zhang, H.; Davison, W. Use of diffusive gradients in thin films to measure cadmium speciation in solutions with synthetic and natural ligands: comparison with model predic tions. Environ. Sci. Technol. 2005, 39, 624-630.

38. Tipping, E.; Rey-Castro, C.; Bryan, S. E.; Hamilton-Taylor, J. Al(III) and Fe(III) binding by humic substances in freshwaters, and implications for trace metal speciation. Geochim. Cosmochim. Acta $2002,66,3211-3224$

39. Xue, H.; Sigg L. A review of competitive ligand-exchange/voltametric methods for speciation of trace metals in freshwater. In Environmental Electrochemistry: Analysis of Trace Element Biogeochemistry; Rozan, T. F.; Taillefert M., Eds. American Chemical Society: Washington DC, 2002; Vol. 811, pp 326-370.

40. Meylan, S.; Odzak, N.; Behra, R.; Sigg L. Speciation of copper and zinc in natural freshwater: comparison of voltammetric measurements, diffusive gradients in thin films (DGT) and chemical equilibrium models. Anal. Chim. Acta 2004, 510, 91-100.

41. van Leeuwen, H. P.; Town, R. M. Kinetic limitations in measuring stabilities of metal complexes by Competitive Ligand Exchange - Adsorptive Stripping Voltammetry (CLE-AdSV). Environ. Sci. Technol. 2005, 39, 7217-7225.

42. Kalis, E. J. J., Weng, L. P., Dousma, F., Temminghoff, E. J. M., \& Van Riemsdijk, W. H. Measuring free metal ion concentrations in situ in natural waters using the Donnan Membrane Technique. Environ. Sci. Technol. 2006, 40, 955-961. 